\title{
Vulnerability and Poverty in Bangladesh ${ }^{*}$
}

\author{
Md. Shafiul Azam \\ Economics, School of Social Sciences, University of Manchester, UK \\ \& \\ Katsushi S. Imai \\ Economics, School of Social Sciences, University of Manchester, UK
}

24 April 2009

\begin{abstract}
This study estimates ex ante poverty and vulnerability of households in Bangladesh using Household Income and Expenditure Survey (HIES) data in 2005. Our results show that poverty is not same as vulnerability as a substantial share of those currently above the poverty line is highly vulnerable to poverty in the future. The study finds that those without education or agricultural households are likely to be the most vulnerable. The geographical diversity of vulnerability is considerable, for example, vulnerability in coastal division, i.e., Chittagoan Division is almost double to that of Dhaka and almost four times higher than Khulna Division. It is suggested that ex ante measures to prevent households from becoming poor as well as ex post measures to alleviate those already in poverty should be combined in evaluating poverty. For the chronic poor who lack economic assets, priority should be given to reduction of consumption fluctuations and building up assets through a combination of protective and promotional programmes. Access to financial services, for example, though micro credit programmes, might help poor households build up assets as it smoothes income and consumption, enables the purchase of inputs and productive assets, and provides protection against crises.
\end{abstract}

Key words: poverty, vulnerability, risks, poverty dynamics, Bangladesh

JEL codes: C21, C25, I32

\footnotetext{
${ }^{*}$ The authors are grateful to the financial support from DFID and Chronic Poverty Research Centre at the University of Manchester in the UK. The authors benefited from the advice from Armando Barrientos, Raghav Gaiha, and Raghbendra Jha. The views expressed are those of the authors' and do not necessarily represent those of the organisation to which they are affiliated.
} 


\section{Vulnerability and Poverty in Bangladesh}

\section{Introduction}

The concept of risk and its contribution to poverty dynamics is gaining increasing importance in poverty literature. It is now evident that the dynamic conceptualization of poverty is important from both theoretical and policy perspectives in designing and implementing anti-poverty policies. Theoretically, the presence of risks can potentially influence household decision making, for example, on whether to adopt a new agricultural technology or whether to have more children in an effort to mitigate future income generation risks. An adequate understating of risk-poverty linkage is also "beneficial in identifying some of the key micro-level binding constraints to poverty reduction: identifying who are the most vulnerable, as well as what characteristics are correlated with movements in and out of poverty, can yield critical insights for policy makers” (Ajay and Rana, 2005). Thus, to address poverty reduction as a goal, public policies should not only highlight poverty alleviation interventions to support those who are identified as the poor ex post, but also the poverty 'prevention' interventions to help those who are poor ex ante, that is, prevent those who are vulnerable to shocks not to fall into poverty. The latter was emphasised by the World Bank's Social Risk Management framework which highlights three types of risk management strategies: prevention, mitigation and coping (Holzmann and Jørgensen, 2000). An assessment of household's vulnerability to poverty is more than justified to figure out who is likely to be poor, how poor are they likely to be, and why they are vulnerable to poverty.

Economic growth in Bangladesh in the last one and a half decades or so has no doubt improved the living standard of the population across the country. Analysis of poverty trends has showed a consistent decline in poverty incidence, especially in rural areas (see Table 1). Bangladesh has enjoyed a credible record of sustained growth within a stable macroeconomic framework in recent years. At a comparatively low level of development, it has also earned the distinctions of a major decline in population growth rate and of graduating to the medium human development group of countries by UNDP's ranking. Child mortality was halved during the 1990's, life expectancy has increased from 45 in 1972 to 64 years in 2005 , net primary enrolment 
went up significantly as did women's economic participation, gender parity has been achieved in primary and secondary education thanks mainly to school stipend or food for education programme (e.g. 978 female students per 1000 male students). Notwithstanding specific areas of progress, aggregate poverty rates remain dauntingly high. Pockets of extreme poverty persist and inequality is rising. Estimates based on the Household Income and Expenditure Surveys (HIES) of the Bangladesh Bureau of Statistics show poverty declines from 58.8 in 1991/92 to 48.9 per cent in 2000 and it further declines to 40.0 per cent in 2005. So poverty has declined slightly more than one percentage point a year since 1990s. The observed improvement also holds true for the distributionally sensitive poverty measures - the poverty gap ratio declined from 17.2 to 12.9 per cent and the squared poverty gap ratio declined from 6.8 to 4.6 per cent- indicating that the situation of the poorest also improved during this period. Despite this improvement, the proportion of the poorest remained worryingly high at around 25 per cent of the population in 2005.

There is considerable interface between the poverty dynamics and unfavourable agro-ecological and climatic environment (e.g. soil salinity, flood, cyclone, river erosion, draught etc.). Other factors contributing to this interface include low human capital accumulation, unregulated and highly informal labour market, health hazards and illness, harvest and social risks like weak rule of law resulting in crime, violence and insecurity, political unrest and corruption. There are indications that a large number of households hover around the poverty line, which implies that high ratio of households can potentially fall back into poverty. According to Ajay and Rana (2005) recent growth experience in Asia -despite having led to dramatic declines in US\$1-aday poverty- is less rosy when more generous US\$2-a-day poverty line is used. Staggeringly large numbers are at the "margin”, indicating potential vulnerabilities to myriad shocks for large proportion of population. Bangladesh alone has almost 68 million individuals in this range. A dynamic forward looking analysis of poverty would lead us to understand the causes of poverty persistence and thereby help bring sharper pro-poor orientation of the growth process where an inclusive social protection mechanism could play a central role.

Taking into account the dynamic dimensions of poverty, the present study estimates the ex ante welfare of households as opposed to the traditional poverty 
assessments, which can only present a static and ex post picture of households' welfare. We estimate ex ante both the expected mean and as well as variability of consumption, with the later being determined by idiosyncratic and covariate shocks.

A number of approaches have been proposed to assess and estimate vulnerability to poverty. First, vulnerability can be seen as a probability of falling into poverty in near future (Chaudhuri, 2003; Chaudhuri et al., 2002; Christaensen and Subbarao, 2001). The other way of measuring vulnerability considers it as low expected utility (Ligon and Schechter, 2003). Both of these measures have their advantages and disadvantages. ${ }^{1}$ In either cases the underlying idea is to construct appropriate probability distribution of consumption expenditures conditional on household characteristics and subject to idiosyncratic/or covariate shocks. This probability distribution function is then used to estimate vulnerability indicators that are similar to the family of FGT indices of poverty (Foster et al., 1984). Ideally, vulnerability measurement would require the long panel data. However, for many developing countries, reliable panel data are scarce and only cross-sectional survey data are available. Furthermore, most household surveys are not designed to provide a full account of the impact of shocks. Information on idiosyncratic and covariate shocks is therefore either completely missing or very limited in most of the household survey data. Bangladesh is no exception in this regard. Although there have been regular rounds of Household Income and Expenditure surveys in every five year intervals, any nationally representative household panel survey is yet to be available. The absence of nationally representative panel data obliges us, in our assessment of vulnerability to poverty in Bangladesh, to adopt the approach proposed by Chaudhuri (2003) which is particularly designed for cross-section data.

Poverty reduction has been, and will remain the principal objective of development policy of Bangladesh for some foreseeable future to come. Although Bangladesh has experienced a moderate growth rate with sustained macro-economic stability, it has one of the most adverse agro-ecological and climatic interfaces. Natural disaster, such as, flood, cyclone, salinity, draught, is fairly common events in the everyday life of Bangladeshis. In addition to the unfriendly eco-climatic conditions, poor economic and social infrastructure contributes to the prevalence of

\footnotetext{
${ }^{1}$ For a detailed survey of literature, refer to Hoddinott and Quisumbing (2003), Hoogeveen (2001) and
} Ligon and Schechter (2004). 
ever present risks that households need to cope with. The principal motivation of the present analysis is thus to explore the following questions: i) Who is vulnerable to poverty and what are the characteristics of households with vulnerability in Bangladesh?; ii) Do the characteristics featuring households with poverty and households with vulnerability differ?; and iii) Who are more likely to fall into transient poverty or chronic poverty and what are the major characteristics of households in transient and chronic poverty, respectively in Bangladesh? The core objectives of this study include measuring poverty and vulnerability to poverty in Bangladesh and suggesting some policy options for government to adopt for reducing poverty and vulnerability. Despite the abundant literature and discourse of poverty in Bangladesh, the rigorous quantitative studies to address the risks and poverty are scarce. This paper is to fill the gap by examining quantitatively the linkage between risks and movement in and out of poverty using nationally representative crosssection data.

The rest of the paper is structured as follows. Section II provides a brief overview of the current state of Bangladesh economy along with the poverty situations and discourses. Section III outlines the details of the methodology, including the one to decompose poverty and vulnerability. Section IV gives a brief description about the data. The econometric and other relevant results are presented in Section V. Section VI concludes the study highlighting some of the policy issues for reducing poverty and vulnerability to poverty in Bangladesh.

\section{Poverty and Vulnerability in Bangladesh}

Bangladesh has long been seen as the archetypal theatre of poverty. Although the history of poverty in the region goes back to the British colonial period (Siddiqui, 1982), the actual surge of interests on poverty among academics and researchers began after the independence of the country in 1971 especially against the backdrop of painful and devastating famine of 1974 and the following decades saw a stream of studies generating the huge literature on poverty issues of Bangladesh. Most of the studies during the 1970s and 80s were ex post static analysis and focused mainly on counting the poor. However, the statistics on poverty are generally problematic due mainly to the quality of the data and the use of multiple sources in estimating poverty. The later half of the 1990s witnessed a shift from static to dynamic analysis of 
poverty. A number of studies investigating the dynamic aspects of poverty in Bangladesh are available now and notable contributions are made by Rahman (1996) and Sen (2003). Below is presented a summary of poverty trends and poverty dynamics in Bangladesh.

Table 1: Poverty Trends in Bangladesh 1983 to 2005

\begin{tabular}{lccccc}
\hline Year & National & Urban & Rural & Poverty Gap & $\begin{array}{c}\text { Squared } \\
\text { Poverty Gap }\end{array}$ \\
\hline $1983 / 84$ & 52.3 & 40.9 & 53.8 & 15.0 & 5.9 \\
$1988 / 89$ & 47.8 & 35.9 & 49.7 & 13.1 & 4.8 \\
$1991 / 92$ & 49.7 & 33.6 & 52.9 & 14.6 & 5.6 \\
$1995 / 96$ & 53.1 & 35.0 & 56.7 & 15.5 & 5.7 \\
2000 & 49.8 & 36.6 & 53.1 & 13.8 & 4.8 \\
2005 & 40.0 & 28.4 & 43.8 & 9.8 & 3.1 \\
\hline
\end{tabular}

Source: Sen 2003 and the figure for 2005 is taken from Bangladesh Bureau of statistics 2005

There is little agreement between researchers and academics about the poverty figures over time due mainly to different methods and multiple sources of data used in estimating poverty during the 1970s and 1980s. The official figure for the estimated level of poverty of the country immediately after independence stood as high as 82.9 per cent in 1973-74. The later half of the 1970s marked the beginning of a rapid decline of poverty followed by a hiatus during the 1980s, poverty continued to decline during the 90s and the pace of reduction got even faster during the fast half of the 2000s as can be seen in Table 1. Poverty has declined from over 80 per cent in the early 1970s to around 40 per cent in $2005 .^{2}$ People living below the poverty line have declined almost 1.5 percentage point a year since 1990s which is quite impressive. More importantly, analysis based on the distributionally sensitive poverty measures indicates that there has been a substantial improvement in the living standards of the poorer section of the population during the period 2000-05 as revealed by a greater decline in the depth and severity of poverty in rural areas than in the urban areas.

\footnotetext{
${ }^{2}$ Overtime comparability of poverty estimates are difficult due mainly to changes in the methodology of data collection and poverty estimation. It is convenient to consider the period between 1995/96 2005 when the Household Income and Expenditure Survey (HIES) began to use consistent data collection and poverty estimation methodologies. For details around these issues please see Ahmed (2000).
} 
Nonetheless, the impressive poverty reduction record is a little comfort as the challenges ahead are quite enormous.

First, poverty still remains at a very high level and the number of people living below poverty line remains almost the same as it was in 1991-92 (about 60million). The most startling consequence of widespread poverty is that a quarter of the country's population -36 million people - cannot afford an adequate diet, according to the 2005 estimates of food poverty or extreme poverty (BBS, 2006). Chronically underfed and highly vulnerable, they remain largely without assets (other than their own labour power) to cushion lean-season hunger or the crushing blows of illness, flooding, and other calamities (Quisumbing, 2007).

Second, faster poverty reduction during the 1990s was also accompanied by rising inequality measured by private consumption expenditure distribution which is a major concern for policy makers. During the period 1991-2000, the level of consumption inequality increased from 31.9 to 37.9 per cent in urban areas and from 25.5 to 29.7 per cent in rural areas. Rising inequality has the potential to dampen the pace of economic growth as well as the poverty reduction outcomes (Sen, 2003).

Third, there are significant regional variations of poverty. Poverty is more pronounced in some areas and regions of the country, which suffer from flooding, river erosion, mono cropping and similar disadvantages. Poverty is highest in the western region of the country (Rajshahi Division) followed by Khulna and Chittagong.

Finally, while these static point-in-time poverty estimates are useful to have a snapshot of poverty situation, they are not much useful to explain the gross movement of households in and out of poverty. Empirical evidence suggests that the gross movements in and out of poverty are much larger than the net aggregate poverty outcomes indicated by static estimates. To have a proper grip on policy perspectives, it is necessary to understand the underlying dynamism that propels households in and out of poverty.

There are a number of studies (e.g. Rahman, 1996, 2002; Sen 1996, 2003) that incorporate the notion of risks and vulnerability in understanding the dynamics of poverty particularly in rural areas of Bangladesh. The panel study of 62 villages by 
BIDS (Bangladesh Institute of Development Studies) and Power and Participation Research Centre (PPRC) was one of the earliest of this nature. It has been found that the poor are not just a simple homogenous population that can be neatly categorized into one or two groups. There are considerable variations and mobility among the poor. Apart from the limited asset base and adverse socio-political environment, the poor and the vulnerable are subject to periodic shocks such as natural disasters, illness and insecurity which often result in fluctuating economic fortunes. There are also factors that help them move out of poverty. Using a two period panel (1987/88 and 2000) consisting of 379 households from 21 villages, Sen (2003) has made similar attempts to explore the dynamics of poverty in rural areas. He adopts the rural livelihood framework coined by Ellis (2000) to analyse (the lack of) mobility of households in and out of poverty and identifies four groups: i) the 'always poor' who remained poor in both periods and constitutes 31 per cent of the sampled households; ii) the 'never poor' who stayed out of poverty in both the periods with the share of 25 per cent; iii) the 'ascending households', the ones who escaped from poverty and represents 26 per cent of the households; and iv) the 'descending households' who descended from the non-poor into poverty with the share of 18 per cent. The difference between the share of the 'ascending' and the 'descending' households, 8 per cent is the net change in poverty during this period. The study again confirms that the mobility among the poor and vulnerable is far greater than what we observe net aggregate poverty changes at national level. More recently, Quisumbing (2007) reports similar movements of households in and out of poverty. All these studies, however, are based on the ex post analysis. The present study attempts to complement the earlier studies by using the measures of ex ante analysis of poverty.

\section{Methodology}

In this section we delineate the detailed estimation procedure of the analysis of vulnerability to poverty in Bangladesh. First, using record level household data, FGT measures of head-count poverty (Foster et al, 1984) will be calculated. Then household's expected consumption will be calculated using Feasible Generalized Least Square (FGLS) estimation procedure. The expected consumption then will be used to estimate household's vulnerability to poverty. 


\section{(1) Measuring Vulnerability}

The principal aim of a forward looking vulnerability to poverty estimation is to have an estimate of household's over time mean and variance of consumption expenditures. Ideally, this requires panel data collected over a sufficiently long period. However, as noted by Jalan and Ravallion (2001), most of the available standard data sources are based on a 'single visit' (cross section) household survey and cannot be used for this purpose. In this study, we use the vulnerability to poverty measure proposed by Chaudhuri (2003), Chaudhuri et al. (2002) and Suryahadi and Sumarto (2003) developed particularly for cross-section data. Vulnerability in this context is defined as expected poverty, or in other words as the probability that a household's consumption will lie below the predetermined poverty line in the near future.

Following Chaudhuri (2003), for a given household $h$, the vulnerability is defined as the probability of its consumption being below poverty line at time $t+1$ :

$$
V_{h t}=\operatorname{Pr}\left(\ln c_{h, t+1}<\ln \underline{c}\right)
$$

where $V_{h t}$ is vulnerability of household $h$ at time $t, c_{h, t+1}$ denote the consumption of household $h$ at time $t+1$ and $\underline{c}$ stands for the poverty line of household consumption.

Assuming that for household $h$ the data generation process for consumption is captured by the following equation:

$$
\ln c_{h}=X_{h} \beta+\varepsilon_{h}
$$

where $c_{h}$ stands for per capita consumption expenditure for household $h, X_{h}$ represents a vector of observable household characteristics (containing both idiosyncratic and community elements), $\beta$ is a vector of parameters, and $\varepsilon_{h}$ is a mean-zero disturbance term that captures household's idiosyncratic factors (shocks) contributing to differential level of per capita consumption for households that share the same characteristics.

Consumption expenditures, $c_{h}$ is assumed to be log-normally distributed and as such the disturbance term, $\varepsilon_{h}$ will be distributed normally. The vulnerability to poverty of household, $h$ with characteristics $X_{h}$ can now be calculated using the coefficient estimates of the equation (1) in the following manner: 


$$
\hat{V}_{h}=\hat{\operatorname{Pr}}\left(\ln c_{h}<\underset{-}{\ln c_{-}} \mid X_{h}\right)=\Phi\left(\frac{\ln \underset{-}{c-X_{h} \hat{\beta}}}{\hat{\sigma}}\right)
$$

where $\hat{V}_{h}$ denotes vulnerability to poverty, that is the probability that the per capita consumption level $\left(c_{h}\right)$ will be lower than the poverty line $(\underline{c})$ conditional on household characteristics $X_{h}$. Meanwhile, $\Phi($.$) denotes the cumulative density of the$ standard normal distribution and $\hat{\sigma}$ is the standard error of the equation (1).

Households future consumption is further assumed to be dependent upon uncertainty about some idiosyncratic and community characteristics. To have consistent estimate of parameters, it is necessary to allow heteroskedasticity, that is, variances of the disturbance term to vary. This can take the following functional form:

$$
\sigma_{e, h}^{2}=Z_{h} \theta=\sum_{i} \sum_{j \geq i} X_{h}^{i} X_{h}^{j} \theta_{i j}+\eta_{h}
$$

A three-step Feasible Generalised Least Squares (FGLS) procedure can be used to estimate the parameter, $\theta$. Equation (1) is first estimated using an ordinary least squares (OLS) procedure. Then, the estimated residuals from the equation (1) are used to estimate the following equation, again by OLS:

$$
\hat{e}^{2}{ }_{O L S, h}=Z_{h} \theta+\eta_{h}=\sum_{i} \sum_{j \geq i} X_{h}^{i} X_{h}^{j} \theta_{i j}+\eta_{h}
$$

The estimate from above is then used to transform the equation (4) into the following:

$$
\frac{{\hat{e^{2}}}^{2}}{Z_{h} \hat{\theta}_{\text {OLS }}}=\left(\frac{Z_{h}}{Z_{h} \hat{\theta}_{O L S}}\right) \theta+\frac{\eta_{h}}{Z_{h} \hat{\theta}_{O L S}}
$$

This transformed equation is estimated using OLS to obtain an asymptotically efficient FGLS estimate, $\hat{\theta}_{F G L S} . Z_{h} \hat{\theta}_{F G L S}$ is a consistent estimate of $\sigma_{e, h}^{2}$, which is the variance of the idiosyncratic component of household consumption.

This is then used to transform the equation (1) into:

$$
\frac{\ln c_{h}}{\sqrt{Z_{h} \hat{\theta}_{F G L S}}}=\left(\frac{X_{h}}{\sqrt{Z_{h} \hat{\theta}_{F G L S}}}\right) \beta+\frac{e_{h}}{\sqrt{Z_{h} \hat{\theta}_{F G L S}}}
$$


OLS estimation of the equation (6) yields a consistent and asymptotically efficient estimate of $\beta$. The standard error of the estimated coefficient, $\hat{\beta}_{F G L S}$, can be obtained by dividing the reported standard error by the standard error of the regression. Finally, the estimates of $\beta$ and $\theta$ obtained through this FGLS method can be used to estimate the vulnerability to poverty of household $h$ through the following generalisation of the equation (2):

$$
\hat{V}_{h}=\Phi\left(\frac{\ln c-X_{h} \hat{\beta}}{\sqrt{\sum_{i} \sum_{j \geq i} X_{h}^{i} X_{h}^{j} \hat{\theta}_{i j}}}\right)
$$

Clearly, estimation of vulnerability to poverty depends on the following elements: the distributional assumption of normality of log consumption, the choice of poverty line $\underline{c}$, the expected level of log consumption and the expected variability of log consumption. The higher the level of expected consumption and expected consumption variability the lower is the vulnerability.

As noted earlier, a merit of this vulnerability measure is that it can be estimated with cross section data. However, the measure correctly reflects a households' vulnerability only if the distribution of consumption across households, given the household characteristics at time $t$ represents time-series variation of household consumption. Hence this measure requires a large sample in which some households experience good times and others suffer from some kind of negative shocks. Also the measure is unlikely to reflect large unexpected shocks, if we use the cross-section data for a normal year.

\section{(2) Determinants of vulnerability}

It is evident from the literature and the empirical studies that vulnerability is a closely related but distinct concept from poverty on a number of counts. First vulnerability is a dynamic concept as opposed to poverty which is essentially a stock concept. The model below is used to examine the determinants of vulnerability to poverty in Bangladesh. This is implemented using the following regression model:

$$
\hat{V}_{h t}=X_{h} \psi+\mu
$$


Where $\hat{V}_{h t}$ is the estimated vulnerability by (7), $X_{h}$ is the vector of household idiosyncratic characteristics, $\psi$ is vector of coefficients and $\mu$ the error term.

\section{(3) Decomposing Poverty and Vulnerability}

The objectives of the present study include creating household's current poverty and vulnerability to poverty profiles and thereby figuring out prospective course of poverty in Bangladesh. In doing so, households will be disaggregated first by location namely -urban and rural and then by various household characteristics that distinguishes between groups, for example- size of land holding in rural areas and educational level of the head of the household in urban area. Head Count Poverty index is calculated using the poverty lines suggested by Bangladesh Bureau of Statistics (BBS). BBS used two poverty lines for its poverty estimates. One is called the lower poverty line which is equal to only the food poverty line ${ }^{3}$ and households whose total expenditures are equal to the food poverty line are called the extreme poor. The other one is the upper poverty line which is equal to food plus non-food poverty line ${ }^{4}$ and the corresponding households are termed as moderate poor households. These two poverty lines -lower and upper- are available for the entire 16 stratum of the HIES 2005. However, in this study we have used only the upper poverty lines for the entire 16 stratum as it includes both the food consumption expenditures and the cost of non-food items. People living below the upper poverty line are generally considered as poor. Whereas lower poverty line only considers the food consumption expenditure and the people living below the lower poverty line is categorized as extreme poor.

Any operationally useful assessment of households' vulnerability status depends essentially on two important factors: first, the choice of a vulnerability threshold, that is, a minimum level of vulnerability above which all households are defined to be vulnerable and second, specifying the time horizon over which households' vulnerability is to be assessed. There is, however, a certain degree of arbitrariness involved in making such decisions.

\footnotetext{
${ }^{3}$ Food poverty line is defined as the cost of acquiring a food basket containing the nutritional requirement of $2122 \mathrm{k} . c a l$. per person per day.

${ }^{4} \mathrm{~A}$ non-food poverty line is calculated by estimating the cost of consuming non-food goods by the households close to food poverty line.
} 
The most preferred and natural candidate for the vulnerability threshold is 0.5. This midway dividing point has three attractive features (Suryahadi and Sumarto, 2003). Firstly, this is the point in the equation (7) where the expected log consumption coincides with the log of the poverty line. Secondly, it makes intuitive sense to say a household is 'vulnerable' if it faces a 50 per cent or higher probability of falling into poverty in the near future. Thirdly, if a household is just at the poverty line and faces a mean zero shock, then this household has a one period ahead vulnerability of 0.5. This implies that, in the limit, as the time horizon goes to zero, then being "currently in poverty" and being "currently vulnerable to poverty" coincide (Pritchett et al., 2000). Another threshold that makes sense is the observed headcount ratio. The underlying logic is that "because the observed poverty rate represents the mean vulnerability level in the population, anyone whose vulnerability level lies above this threshold faces a risk of poverty that is greater than the average risk in the population and hence can be legitimately included among the vulnerable” Chaudhuri (2003, P11). In practice, however, most of the empirical studies adopted the vulnerability threshold of 0.5 .

The other but not less important aspect of an operationally useful vulnerability index is to decide on a time horizon over which households' vulnerability is to be assessed. The existing literature again is of little help in this regard. In most of the cases time horizon is defined through some arbitrary expression like "probability of falling into poverty in the near future" providing indication that there is no obvious choice. Recognizing that certain degree of arbitrariness is needed, Chaudhuri (2003) proposed two possible cases -a time horizon of one year, which can be thought of in terms of the likelihood of poverty in the short run, and a time horizon of three years which roughly corresponds to the likelihood of poverty in the medium-term. In the later case all households experience poverty spell at least once in the next three years are categorised as vulnerable.

With a vulnerability threshold $V_{n}=0.5$ indicting the probability of falling into poverty at least once in the next $n$ years, the probability of falling into poverty in the subsequent years, i.e., one , two or three years can be calculated using the following equation:

$$
V^{*}=1-\sqrt[n]{1-V_{n}}
$$


Table 2 shows the different vulnerability threshold for three different years.

Table 2: The Relationship of Time Horizon and Vulnerability Threshold

\begin{tabular}{lcc} 
& Time horizon & Vulnerability threshold \\
& $V n=0.50$ \\
\hline One year & 0.500 \\
Two year & 0.292 \\
Three year & 0.206 \\
\hline
\end{tabular}

Once decisions about vulnerability threshold and time horizon are taken, using a combination of household poverty and vulnerability to poverty status based on current consumption, the estimated degree of vulnerability to poverty, and the estimated expected consumption, households can now be grouped into several poverty and vulnerability categories as in Table $3^{5}$.

Table 3 Poverty and Vulnerability Categories

\begin{tabular}{|c|c|c|c|c|c|}
\hline & & \multicolumn{2}{|c|}{ Current Consumption (c) } & & \\
\hline & & $C<C$ & $C \geq C$ & & \\
\hline \multirow{3}{*}{ 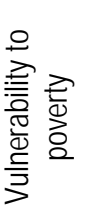 } & \multirow{2}{*}{$v \geq 0.5$} & A & D & $E[c]<c$ & \multirow{3}{*}{ 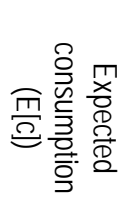 } \\
\hline & & B & $E$ & \multirow{2}{*}{$E[c] \geq c$} & \\
\hline & $v<0.5$ & C & $\mathrm{F}$ & & \\
\hline
\end{tabular}

Poor $=A+B+C$

- Chronic Poor = A

- Transient Poor = B + C

Non-poor $=\mathrm{D}+\mathrm{E}+\mathrm{F}$

- High Vulnerability Non-poor $=\mathrm{D}+\mathrm{E}$

- Low Vulnerability Non-poor = F

High Vulnerability Group $=A+B+D+E$

- Low Level of Consumption = A + D

- High Variability of Consumption = B + E

Low Vulnerability Group $=\mathrm{C}+\mathrm{F}$

Total Vulnerable Group $=A+B+C+D+E$

Here, $\underline{\underline{c}}$ is the poverty line consumption.

\footnotetext{
${ }^{5}$ The categorization of poverty and vulnerability to poverty of households is based on Suryahadi and Sumarto (2003).
} 
The above categorization process thus would result in a number of overlapping groups of households. First, the population is divided into two distinct groups using the poverty line consumption threshold: the 'poor' and the 'non-poor'. Those who have average consumption equal to or below the poverty lines are generally termed as the 'poor' and the rest is 'non-poor'. The poor then are decomposed into two distinct groups: the 'chronic poor' and the 'transient poor'. The chronic poor are the ones who are currently poor and also have expected consumption levels below the poverty line. These household are most likely to remain poor in future. The transient poor, on the other hand, are those who are also currently poor but their expected consumption levels are above the poverty line. Some of the transient poor have low vulnerability, but some of them have high vulnerability. As a result of this process, a total of five groups of households will emerge: the 'poor', the 'non-poor', the 'high vulnerability group', the 'low vulnerability group', and the 'total vulnerable group'.

As can be seen from the taxonomy above, the characteristic feature of the high vulnerable household group are 'low level of expected consumption' and 'high variability of consumption'. Similarly, the non-poor can also be partitioned into two separate groups — the 'vulnerable non-poor' and the 'non-vulnerable non-poor' depending on their degree of vulnerability, expected level of consumption and the initial poverty status. The constituents of the 'total vulnerable group' are then the households associated with high vulnerability group and those are currently poor. This kind of categorization is important from both theoretical and practical point of views. First, it supports the idea that the poor and the vulnerable are not the same - they are distinct groups even though they may not be mutually exclusive. The total vulnerable group thus includes all those who are currently poor plus those people who are currently non-poor but who have a relatively strong chance of falling into poverty in the near future. As Suryardi and Sumarto (2003, p.7) noted:

while vulnerability to poverty is defined as the risk or probability of falling below the poverty line, the definition of the total vulnerability group is based on both this risk as well as initial poverty status. This is ... to categorize a household as vulnerable it is necessary to combine the probability of bad outcomes as well as some measure of their 'badness' according to a given social welfare function. 
There are obvious advantages in further disaggregation of poverty categories as in Table 3, rather than simply dividing households into the poor and the non-poor. This disaggregation clearly demonstrates that the poor and the vulnerable are heterogeneous rather than static homogenous groups. It will facilitate advocacy, allow monitoring of progress in reducing vulnerability. In addition, each one of these groups is likely to respond differently to particular policies aimed at reducing poverty and vulnerability and as such, it might be necessary to devise different policies for different groups (Jalan and Ravallion, 2000).

\section{Data}

For measuring poverty and vulnerability and investigating the relationship between the two, detailed information are required on characteristics of households such as household size, demographics and resource endowments, and their income and consumption expenditure. Net income refers to the household's income in cash and in kind after deducting all costs and taxes. Consumption expenditure is the expenditure on food and non-food items such as clothing, housing, health, education, transport and communication, recreation and entertainment.

This study uses the 'Household Income and Expenditure Survey' (HIES)-2005 collected by the Bangladesh Bureau of Statistics (BBS). It was conducted during January 2005 to December 2005. There are 10 different modules containing a wide range of individual and household level information. It has specific modules for general household characteristics as well as modules on health, education, activities, employment and labour force participation, assets and income, prices, consumption expenditures of all kinds, social safety net programmes etc.

HIES-2005 is a nationally representative household survey, covering all areas of the country. A total of 10,080 household were interviewed of which 6,400 is rural and the rest 3,680 is urban. A two stage stratified random sampling technique was followed in drawing sample for HIES 2005 under the framework of Integrated Multipurpose Sample (IMPS) design developed on the basis of Population and Housing Census 2001. There are 320 rural and 184 urban PSUs in the sample.

HIES-2005 collected some selected community/village level information as well. However, community information was collected only from the rural areas. The community information includes principal economic activities of the village, physical 
and other social infrastructure, availability of other facilities like marketing, banks, and the information on impact of natural disasters.

\section{Econometric Results}

The results of 'the regression equation' are given in Table 4. It shows the regression results for the equation (7) whereby log of per capita consumption in 2005 is estimated by household idiosyncratic characteristics and other determinants. The summary statistics of variables included in the model are given in the Appendix. The variables 'size of the households', 'age of head of the households' and the 'size of land holding' by households along with their squares are included in the model because of the possible non-linearity of the relationship between log consumption per capita and these variables. Other variables reflecting household's idiosyncratic characteristics are dependency ratio, hygienic conditions, whether a household has electricity, telephone connection or not, and whether households do participate in social safety net programmes or not. Household's hygienic condition is defined as bad if a household does not have sanitary latrine and safe drinking water. Other important inclusions are housing condition, educational level achieved by the head of the household, activity status of the head of the household, and whether head of the household suffered any chronic or serious illness over the past twelve months. While the variables other than the housing condition seem to be natural candidates for inclusion in the regression (Suryahadi and Sumarto, 2003), housing condition defined by the type of the construction materials used in building houses, is included in the model as this is thought to be a major and quite regular source of shocks for Bangladeshi households. Even with moderate rainfall and normal flooding conditions, which is fairly common in Bangladesh, households particularly in rural areas need to spend significant amount of resources for repair and reconstruction of their houses. So houses constructed by mud brick, hemp/hay/bamboo are considered to be poor while brick/tiles/ C. I. sheet/wood houses are considered to be good houses. Activity of the head of the household is categorized into three categories: household head with no activity meaning either they are retired or unemployed, household-heads engaged in agricultural activities, and household heads working in non-agricultural sector. Similarly, households are categorized into four distinct groups in accordance with the educational level achieved by the head of the households as can be seen in the Appendix. 
Table 4: Estimates of Expected log Consumption

\begin{tabular}{|c|c|c|}
\hline Variable labels & $\begin{array}{l}\text { Log consumption } \\
\text { Coefficients } \\
\text { (robust t statistic) }\end{array}$ & $\begin{array}{c}\text { Vulnerability } \\
\text { Coefficients } \\
\text { (robust t statistics) }\end{array}$ \\
\hline Age of head of households & $\begin{array}{c}.017 \\
(10.41)\end{array}$ & $\begin{array}{c}-.018 \\
(-14.26)\end{array}$ \\
\hline Age-square of head of household & $\begin{array}{c}-.000 \\
(-9.22)\end{array}$ & $\begin{array}{c}.000 \\
(11.86)\end{array}$ \\
\hline Size of household & $\begin{array}{c}-.121 \\
(-17.38)\end{array}$ & $\begin{array}{c}.142 \\
(26.86) \\
\end{array}$ \\
\hline Size-square of household & $\begin{array}{c}.005 \\
(10.16) \\
\end{array}$ & $\begin{array}{c}-006 \\
(-16.92)\end{array}$ \\
\hline Total land holding of household & $\begin{array}{c}.098 \\
(20.85) \\
\end{array}$ & $\begin{array}{c}-.103 \\
(-22.55)\end{array}$ \\
\hline Square of total land holding & $\begin{array}{c}-.003 \\
(-7.56) \\
\end{array}$ & $\begin{array}{c}.003 \\
(9.71) \\
\end{array}$ \\
\hline Dependency ratio in the household & $\begin{array}{c}-.337 \\
(-15.76)\end{array}$ & $\begin{array}{c}.406 \\
(25.04) \\
\end{array}$ \\
\hline Dummy of gender of head of household & $\begin{array}{l}0.161 \\
(1.02) \\
\end{array}$ & $\begin{array}{c}.023 \\
(2.03) \\
\end{array}$ \\
\hline Dummy of participating in safety net programme & $\begin{array}{c}.091 \\
(8.78)\end{array}$ & $\begin{array}{c}-.090 \\
\left(-9^{\prime} 76\right)\end{array}$ \\
\hline Dummy of illness of head of household & $\begin{array}{c}-.033 \\
(-3.34) \\
\end{array}$ & $\begin{array}{c}.022 \\
(3.38) \\
\end{array}$ \\
\hline Dummy of having electricity connection & $\begin{array}{c}.172 \\
(20.37)\end{array}$ & $\begin{array}{c}-.223 \\
(-30.22)\end{array}$ \\
\hline Dummy of having telephone line & $\begin{array}{c}.415 \\
(26.99) \\
\end{array}$ & $\begin{array}{c}-.019 \\
(-2.15) \\
\end{array}$ \\
\hline Dummy of hygienic condition & $\begin{array}{c}.110 \\
(13.09) \\
\end{array}$ & $\begin{array}{c}-.119 \\
(-16.03)\end{array}$ \\
\hline Dummy of housing condition & $\begin{array}{c}.105 \\
(13.89) \\
\end{array}$ & $\begin{array}{c}-.187 \\
(-25.32) \\
\end{array}$ \\
\hline Dummy of head of household agricultural activity & $\begin{array}{c}-.115 \\
(-7.36) \\
\end{array}$ & $\begin{array}{c}.096 \\
(8.24) \\
\end{array}$ \\
\hline Dummy of head of household non-agricultural activity & $\begin{array}{c}-.051 \\
(-3.34)\end{array}$ & $\begin{array}{c}.049 \\
(4.62)\end{array}$ \\
\hline Dummy of up to secondary education & $\begin{array}{c}.158 \\
(19.86) \\
\end{array}$ & $\begin{array}{c}-.229 \\
(-32.64) \\
\end{array}$ \\
\hline Dummy of up to higher secondary education & $\begin{array}{c}.298 \\
(13.31) \\
\end{array}$ & $\begin{array}{c}-.207 \\
(-14.71)\end{array}$ \\
\hline Dummy of tertiary or higher education & $\begin{array}{c}.450 \\
(21.08) \\
\end{array}$ & $\begin{array}{c}-.194 \\
(-15.01)\end{array}$ \\
\hline Dummy of Barishal region & $\begin{array}{c}-.262 \\
(-12.36)\end{array}$ & $\begin{array}{c}.344 \\
(20.61)\end{array}$ \\
\hline Dummy of Chittagoan region & $\begin{array}{c}-.021 \\
(-1.33) \\
\end{array}$ & $\begin{array}{c}.079 \\
(5.43)\end{array}$ \\
\hline Dummy of Dhaka region & $\begin{array}{c}.114 \\
(-7.17)\end{array}$ & $\begin{array}{c}.109 \\
(7.74)\end{array}$ \\
\hline Dummy of Khulna region & $\begin{array}{c}-.329 \\
(-19.24) \\
\end{array}$ & $\begin{array}{c}.224 \\
(14.81) \\
\end{array}$ \\
\hline Dummy of Rajshahi reg & $\begin{array}{c}-.315 \\
(-20.57)\end{array}$ & $\begin{array}{c}.252 \\
(17.69)\end{array}$ \\
\hline Constant & $\begin{array}{c}6.63 \\
(153.99)\end{array}$ & $\begin{array}{c}.453 \\
(13.16)\end{array}$ \\
\hline
\end{tabular}


The non-linearity is confirmed in the relationship between log consumption per capita and the size of the household, age of household head, and size of total land holding and their squared terms as their coefficient estimates are statistically significant. The coefficient for 'age of household head' is positive and highly significant. Its square is then negative and statistically significant. Similarly, size of the total land holding seems to affect consumption positively as expected but its square is negative and highly significant. As expected, the size of household has a negative influence on consumption, that is, the larger the households the lower tends to be the per capita consumption. Its square again is of opposite sign indicating the non-linearity of relationship with log of consumption per capita. Not surprisingly, the variables- housing condition, electricity connection, telephone connection, and hygienic condition all have sizeable positive effect on per capita consumption and the coefficients are also highly statistically significant.

Compared to the base category 'illiterate head of household', the rest of dummies on education are found to affect consumption per capita positively. The relevant coefficients are all statistically significant as well. This basically conforms to other studies concluding that literacy and education attainment decrease poverty (e.g. World Bank, 2002). The coefficient for 'dependency ratio' is negative and statistically significant indicating that households with larger number of younger people tend to have lower level of per capita consumption. The relatively larger coefficient for nonagricultural activity dummy indicates that the non-agricultural activity is more rewarding than agricultural activities in terms of per capita consumption.

Table 5 provides estimates for national level poverty and vulnerability to poverty categories. The decomposition of poverty and vulnerability to poverty shows that total vulnerability to poverty at national level is much higher than the point-in-time estimates of poverty, which signifies the importance of forward looking poverty analysis. Arguably, this indicates that the current poverty estimates might be underestimated. The transient poor is estimated to be 15.01 per cent as opposed to the 9.25 per cent 'high vulnerable non-poor' group — people who are currently non-poor but have the potential to become poor some time in future. The high percentage (i.e., 23.55) of chronic poor which is also referred to as structural poverty is in line with BBS's official estimates for extreme poverty rate of around 25 per cent in 2005. Low level of endowments, poor economic infrastructure, and limited opportunities for 
employment among others might explain the prevalence of such huge numbers of chronic poor.

Table5: Poverty and Vulnerability to Poverty Categories, 2005

\begin{tabular}{llc}
\hline & Poverty and Vulnerability Category & (\%) \\
& Poor: & 23.55 \\
\hline A & Chronic poor (CP) & 15.01 \\
B +C & Transient Poor (TP) & $\mathbf{3 8 . 6 4}$ \\
A+B+C & Total poor & 9.25 \\
D+E & High Vulnerable Non-poor (HVNP) & $\mathbf{4 7 . 8 1}$ \\
A +B+C+D+E & Total Vulnerability to Poverty (TVP) \\
\hline
\end{tabular}

Table 6 shows the distribution of population by poverty and vulnerability to poverty categories diaggregated by location namely, urban and rural in 2005. The poverty figures for rural areas indicate that despite increasing efforts for poverty reduction over the years, poverty remains a pervasive factor in rural Bangladesh. Around 42.23 per cent rural population stays below the poverty line while 26.25 per cent of them probably will remain there for a few more years to come. About 16 per cent of the rural households are identified as transient poor some of whom may escape poverty in future while 10.56 per cent rural non-poor are living under the threat of becoming poor in future. The urban area recorded more impressive poverty reduction in recent years than the rural areas as revealed by the corresponding figures in the above table. However, the proportion of transient poor in urban areas as compared with the chronic poor is higher than what it is for rural areas. The high vulnerable non-poor group in urban area represents a sizeable proportion of urban population as well. Almost 19.69 per cent of the urban population is involved in movement in and out of poverty indicating that urban poverty might shot up if appropriate risk mitigating policies along with usual poverty reduction strategies are not in place.

Table 6: Poverty and Vulnerability Categories by Location

\begin{tabular}{llcc}
\hline & Poverty and Vulnerability Categories & Urban & Rural \\
& Poor: & & \\
\hline A & Chronic poor & 15.63 & 26.25 \\
B +C & Transient Poor & 12.16 & 15.98 \\
A+B+C & Total poor & $\mathbf{2 7 . 8 0}$ & $\mathbf{4 2 . 2 3}$ \\
D+E & High Vulnerable Non-poor & 7.53 & 10.56 \\
A+B+C+D+E & Total Vulnerability to Poverty & $\mathbf{3 5 . 3 3}$ & $\mathbf{5 2 . 7 9}$ \\
\hline
\end{tabular}


As shown in Table 7, there is a considerable variation in the poverty and vulnerability to poverty rates among the six administrative divisions of the country. The poverty rate is the highest in the southern and northern part of the country while the central part has the lowest poverty rate. In Barishal Division poverty is as high as 50.23 per cent and the total vulnerability figure is above sixty per cent. Looking at the composition of poverty and vulnerability to poverty categories, variation in rates are quite discernible. While chronic poverty is highest in Barishal closely followed by Chittagaon Division, Khulna has the lowest rate of chronic poverty followed by Dhaka Division. Nonetheless, Khulna shares the highest rate of transient poverty. Chittagaon and Sylhet Division have the highest share of high vulnerable-non-poor population. All these figures again justify the forward looking poverty analysis as it unveils different dimensions of poverty prevalence enabling policy makers to have a deeper understanding of poverty dynamics in the country.

Table 7: Poverty and Vulnerability Category by Administrative Divisions and by Household Characteristics

\begin{tabular}{|c|c|c|c|c|c|}
\hline Name of Division & $\mathrm{CP}$ & TP & Total Poor & HVNP & Total VP \\
\hline Barishal & 29.97 & 20.25 & 50.23 & 9.94 & 60.17 \\
\hline Chittagoan & 28.23 & 5.39 & 33.62 & 18.78 & 52.40 \\
\hline Dhaka & 19.05 & 11.43 & 30.49 & 9.33 & 39.82 \\
\hline Khulna & 16.48 & 27.07 & 43.55 & 3.99 & 47.54 \\
\hline Rajshahi & 27.16 & 21.60 & 48.77 & 5.19 & 53.96 \\
\hline Sylhet & 27.59 & 3.51 & 31.10 & 18.55 & 49.65 \\
\hline Illiterate head of household & 37.20 & 14.89 & 52.09 & 14.56 & 66.63 \\
\hline $\begin{array}{l}\text { Head of household having up to } \\
\text { secondary education }\end{array}$ & 9.04 & 17.27 & 26.31 & 5.12 & 31.43 \\
\hline $\begin{array}{l}\text { Head of household having higher } \\
\text { secondary education }\end{array}$ & .42 & 10.03 & 10.46 & .00 & 10.46 \\
\hline $\begin{array}{l}\text { Head of household having } \\
\text { tertiary level or higher education }\end{array}$ & .04 & 4.24 & 4.28 & .00 & 4.28 \\
\hline No activity head of Households & 9.95 & 16.15 & 26.10 & 6.33 & 32.43 \\
\hline Agricultural & 31.63 & 15.31 & 46.95 & 12.23 & 59.18 \\
\hline Non-agricultural & 21.05 & 14.46 & 35.51 & 8.86 & 44.37 \\
\hline
\end{tabular}


There is virtually no disagreement among economists on the prominent role of education in poverty reduction. Education can affect people's standard of living through a number of channels: it helps skill formation resulting in higher marginal productivity of labour that eventually enables people to engage in more remunerative jobs. Hence it is expected that education is positively correlated with consumption levels of households, that is, the higher the level of education, the higher the households tend to consume and the lower the level of poverty. The regression result reported earlier also confirms this for Bangladesh. The distribution of households belonging to different categories differentiated by the level of education achieved by the head of households across different poverty and vulnerability to poverty groups shows that poverty is most concentrated in households headed by people who do not have any formal education. They are also the most vulnerable in terms of estimated total vulnerability to poverty which is over 60.0 per cent. Poverty and vulnerability get lower and lower as the level of education of household heads get higher and higher. According to this estimate among people who have tertiary or more education, chronic poverty is totally absent and this group of people have better coping abilities against future odds as revealed by the absence of future threat of becoming poor. A meagre 4.24 per cent of highly educated people are transient poor.

The incidence of poverty and vulnerability to poverty across broad sectors: agricultural and non-agricultural. There seems to be a group of households with head of household belonging to neither of the above groups. These are probably the household where head of the household either retired from jobs or households headed by housewives receiving remittances and not involved in any economic activity. Poverty is less prevalent in this group while households with head of households working in agriculture share the majority of poor. Chronic poverty in households with heads working in agriculture is widespread. The high vulnerable non-poor population also constitutes a significant proportion of these households. On the other hand, nonagricultural activities are seen to be more remunerative in terms of reducing poverty as is the case with most other developing countries. Nonetheless, more than 35 per cent of non-agricultural households are chronically poor while almost 9 per cent of the non-poor non-agricultural household are at risk of poverty. 


\section{Concluding Observations}

As has been the case for many other similar studies, particularly for Indonesia, and China, vulnerable population in Bangladesh is also found to be significantly larger than the number of currently poor. Total vulnerability is found to be 47.81 as opposed to the current poverty of around 39 per cent. Vulnerability in rural areas is even higher which is estimated to be 52.79 per cent. The categorization of poverty into transient and chronic poverty is even more insightful. Regional dimension of poverty and vulnerability to poverty clearly shows the justification for this kind of analysis and certainly calls for differential treatment of poverty reduction efforts in different administrative regions. Vulnerability in coastal division, i.e., Chittagoan Division is almost double to that of Dhaka and almost 4 times higher than Khulna Division.

Education is found to be a key element in reducing poverty. Poverty and vulnerability to poverty are the highest among households headed by illiterate person; where as households headed by person having more than higher secondary level education are significantly better poised to cope with risk and uncertainty. So investment in human capital along with other means of social protection and promotion could be instrumental for poverty reduction in Bangladesh. Agricultural households again are more vulnerable than non-agricultural households, which underscores the need for more protection of the agricultural community.

There are reservations among economists about using a single cross-section to estimate standard deviation of consumption and to assume that cross sectional variability proxies inter-temporal variation in consumption (e.g. Hoddinott and Quisumbing, 2003). Nonetheless, the results of this study provide meaningful insights into poverty and vulnerability at household levels in case where only cross-sectional data are available. A sizeable portion of households that are now non-poor are certainly vulnerable to falling into poverty in future. This has policy implications and therefore such results should be taken into account, particularly when policy makers design social policy. Ex ante measures should be enhanced to prevent as many households as possible from becoming poor, so should be ex post measures to alleviate those already in poverty. As noted earlier, the expansion of the concept of poverty does not alter the basic tenets of the usual poverty reduction strategies. The significance of governance, human capital and infrastructure as key drivers of growth, employment generation, and poverty reduction will remain. The only issues that it 
puts ahead is the importance of social protection and promotion programmes for ensuring inclusiveness in the development process so that growth becomes more propoor. However, in designing policies one should take note of the varying nature of poverty and vulnerability. For the chronic poor who lack economic assets, priority should be given to reduction of consumption fluctuations and building up assets through a combination of protective and promotional programmes. Access to financial services, for example, though micro credit programmes, might help poor households build up assets as it smoothes income and consumption, enables the purchase of inputs and productive assets, and provides protection against crises. On the other hand, the transient poor and high vulnerable non-poor households are most likely to benefit from some combination of prevention, protection, and promotion which would give them a more secure base to diversify their activity into higher-return, higher risk activities. 


\section{References}

Ahmed, A. U. (2000) 'Trends in consumption, nutrition, and poverty'. In R. Ahmed, S. Haggblade, and T. E. Chowdhury (eds) Out of the Shadow of Famine: evolving food markets and food policy in Bangladesh. Baltimore: Johns Hopkins University Press for the international Food Policy Research Institute.

Ajay, T. and Rana Hasan (2005) 'Conceptualizing and Measuring Poverty as Vulnerability: Does It Make a Difference?’ ERD Policy Brief Series No. 41. Manila: Asian Development Bank.

BBS (2006) Preliminary Report on Household Income \& Expenditure Survey 2000. Dhaka: Ministry of Planning.

Chaudhuri, S. (2003) 'Assessing vulnerability to poverty: concepts, empirical methods and illustrative examples'. mimeo. New York: Columbia University.

Chaudhuri, S., J. Jalan, and A. Suryahadi (2002) 'Assessing Household Vulnerability to Poverty: A Methodology and Estimates for Indonesia'. Columbia University Department of Economics Discussion Paper No. 0102-52. New York: Columbia University.

Deaton, A. (1997) The Analysis of Household Surveys. Baltimore, MD: Johns Hopkins University Press.

Dercon, S. (2002) 'Income risk, coping strategies, and safety nets', World Bank Research Observer 17(2): 141-166.

Dercon, S. (2004) 'Growth and Shocks: Evidence from Rural Ethiopia', Journal of Development Economics 74(2): 309-329.

Dercon, S. and P. Krishnan, (2000a) 'In sickness and in health: Risk-sharing within households in rural Ethiopia', Journal of Political Economy, Vol. 108: 688-727.

Dercon, S. and P. Krishnan (2000b) 'Vulnerability, seasonality, and poverty in Ethiopia', Journal of Development Studies 36 (6): 25-5.

Foster, J. E., J. Greer, and E. Thorbecke (1984) 'A Class of Decomposable Poverty Indices', Econometrica, 52: 761-766.

Gaiha, R. and K. Imai (2004) 'Vulnerability, Persistence of Poverty and Shocks-Estimates for Semi-Arid Rural India’, Oxford Development Studies, 32(2): 261-281.

GoB, (2002) Bangladesh. A National Strategy for Economic Growth and Poverty Reduction. Economic Relations Division, Ministry of Finance, Government of Bangladesh.

Gunning, J. and C. Elbers (2003) 'Vulnerability in a Stochastic Dynamic Model', Tinbergen Institute Discussion Paper TI 2003-070/2.

Heitzmann, K., R. S. Canagarajah, and P. B. Siegel (2002) 'Guidelines for Assessing the Sources of Risk and Vulnerability’, Social Protection Discussion Paper 0218. Washington DC: World Bank.

Hoddinott, J., and A. Quisumbing (2003) 'Methods for Microeconometric Risk and Vulnerability Assessments’, Social Protection Discussion Paper Series No.0324. Washington DC: The World Bank.

Holzmann, R. and S. Jørgensen (2000) 'Social Protection as Social Risk Management: Conceptual Underpinnings for the Social Protection Sector Strategy Paper’, Journal of International Development 11: 1005-27.

Holzmann, R. and S. Jørgensen (2001) 'A New Conceptual Framework for Social Protection and Beyond', International Tax and Public Finance 8 (4): 529-56.

Hoogeveen, H. (2001) 'A new Approach to Insurance in Rural Africa', The Geneva Papers on Risk and Insurance 26(3): 505-513.

Hossain, M., B. Sen, H.Z. Rahman (2000) 'Growth and Distribution of Rural Income in Bangladesh. Analysis Based on Panel Survey Data', Economic and Political Weekly Vol. XXXV, Nos. 52 and 53, December 30, Mumbai (India). 
Imai, K., R. Gaiha and W. Kang (2007) 'Vulnerability and Poverty Dynamics in Vietnam', Working Paper', The University of Manchester, Manchester.

Jalan, J. and M. Ravallion (2001) 'Household income dynamics in Rural China', Policy Research Working Papers Series, No. 2706. The World Bank.

Jacoby, H. and E. Skoufias (1997) 'Risk, Financial Markets, and Human Capital in a Developing Country', Review of Economic Studies, 64(3): 311-336.

Ligon, E. and L. Schechter (2003) ‘Measuring Vulnerability’, Economic Journal 113 (March): C95-C102.

Ligon, E. and L. Schechter (2004) 'Evaluating Different Approaches to Estimating Vulnerability’. Social Protection Discussion Paper. Washington DC: World Bank.

Morduch, J. (1995) 'Income Smoothing and Consumption Smoothing', Journal of Economic Perspectives 9(2): 103-14.

Morduch, J. (1999) 'Between the Market and State: Can Informal Insurance Patch the Safety Net?’ World Bank Research Observer vol.14 (2): 187-208.

Pritchett, L., A. Suryahadi and S. Sumarto (2000) 'Quantifying Vulnerability to Poverty: A Proposed measure, Applied to Indonesia’. Policy Research Working Paper no. 2437. Washington DC: The World Bank

Quisumbing, A. (2007) 'Poverty transitions, shocks, and consumption in rural Bangladesh: Preliminary results from a longitudinal household survey’. CPRC Working Paper-105. Manchester: Chronic Poverty Research Centre, University of Manchester,

Rahman, H.Z. (1996) Crisis, Income Erosion, and Coping”. In H.Z. Rahman, M. Hossain, and B. Sen (eds), 1987-1994: Dynamics of Rural Poverty in Bangladesh, Bangladesh Institute of Development Studies, Dhaka.

Rahman, H.Z. (2002) 'Poverty: The Challenge of Graduation', Bangladesh Development Studies XXVIII(4):53-78.

Sen, B. (1996) 'Movement in and out of Poverty: A Tentative Explanation', in H.Z. Rahman, M. Hossain, and B. Sen (eds) 1987-1994: Dynamics of Rural Poverty in Bangladesh, Dhaka: Bangladesh Institute of Development Studies.

Sen, B. (2003) 'Drivers of Escape and Decent: Changing Household Fortunes in Rural Bangladesh'. Bangladesh Institute of Development Studies, Dhaka

Siddiqui, K. (1982) Political Economy of Rural Poverty in Bangladesh. Dhaka:NILG

Suryahadi, A. and S. Sumarto (2003) 'Measuring Vulnerability to Poverty in Indonesia Before and After the Crisis'. Paper presented at the $4^{\text {th }}$ Annual GDN International Conference, organized by IPALMO, Cairo (Jan 21).

Tesliuc, E. and K. Lindert (2004) 'Risk and Vulnerability in Guatemala: A Quantitative and Qualitative Assessment'. Social Protection Discussion Paper 408. Washington DC: The World Bank

Vakis, R. (2004) 'Rural Poverty in Afghanistan’. Background note for Poverty, Vulnerability and Social Protection in Afghanistan. South Asia Region: The World Bank

World Bank (2001) Social Protection Sector Strategy: From Safety Net to Springboard.

World Bank. (2002) 'Pakistan Poverty Assessment - Poverty in Pakistan: Vulnerability, Social Gaps, and Rural Dynamics’. Washington, DC. 


\section{Appendix.}

Household Characteristics included in the Model

\begin{tabular}{|c|c|c|}
\hline Variables & Mean & Standard deviation \\
\hline \multicolumn{3}{|l|}{ Age of head of households } \\
\hline Age-square of head of household & 2244.46 & 1350.67 \\
\hline Size of household & 4.86 & 2.07 \\
\hline Size-square of household & 27.91 & 27.16 \\
\hline Total land holding of household & .71 & 1.54 \\
\hline Square of total land holding & 2.88 & 25.17 \\
\hline Dependency ratio in the household 6 & .36 & .22 \\
\hline Dummy of gender of head of household & .89 & .30 \\
\hline Dummy of participating in safety net programme & .88 & .32 \\
\hline Dummy of illness of head of household & .74 & .44 \\
\hline Dummy of having electricity connection & .47 & .50 \\
\hline Dummy of having telephone line & .13 & .34 \\
\hline Dummy of hygienic condition & .53 & .50 \\
\hline Dummy of housing condition & .71 & .45 \\
\hline \multicolumn{3}{|l|}{ Educational level of head of household } \\
\hline Dummy of illiterate head of household & .52 & .50 \\
\hline Dummy of up to secondary education & .37 & .48 \\
\hline Dummy of up to higher secondary education & .04 & .19 \\
\hline Dummy of tertiary or higher education & .05 & .23 \\
\hline \multicolumn{3}{|l|}{ Activity status of head of household } \\
\hline Dummy of no-activity head of household & .14 & .42 \\
\hline Dummy of head of household engaged in agriculture & .34 & .47 \\
\hline Dummy of head of household engaged in non-agricultural activity & .52 & .50 \\
\hline
\end{tabular}

${ }^{6}$ Dependency ratio is defined to be the proportion of the total number of household members who are 15 years of age or younger. 